\title{
Arabian oryx reintroduction in Oman: successes and setbacks
}

\author{
J. A. Spalton, M. W. Lawrence and S. A. Brend
}

\begin{abstract}
The return of the Arabian oryx Oryx leucoryx to Oman symbolized the success of a new approach to species conservation and established reintroduction as a conservation tool. Ten years after the species had been exterminated in the wild by poaching, the first 10 founder oryx, descendants of the 'World Herd', were reintroduced to the desert in central Oman in January 1982. A second release followed in 1984 and the population grew slowly through a 3-year drought that was broken by rain in June 1986. Further years of good rainfall and more founders meant that by April 1990 there were over 100 oryx in the wild, independent of supplementary feed and water, and using a range of over $11,000 \mathrm{sq} \mathrm{km}$. At that time a new monitoring programme was implemented that allowed the transition from individual- to population-based monitoring and management. The population continued to grow and
\end{abstract}

by October 1995 numbered approximately 280 in the wild (of which 22 were surviving founders) and used over $16,000 \mathrm{sq} \mathrm{km}$ of the Arabian Oryx Sanctuary. However, in February 1996 poaching resumed and oryx were captured for sale as live animals outside the country. Despite the poaching the population continued to increase and by October 1996 was estimated to be just over 400 . However, poaching intensified and continued through late 1996 and 1997. By September 1998 it had reduced the wild population to an estimated 138 animals, of which just 28 were females. The wild population was no longer considered viable and action was taken to rescue some of the remaining animals from the wild to form a captive herd.

Keywords Arabian oryx, Oman, Oryx leucoryx, poaching, reintroduction.

\section{Introduction}

In the early 1960 s a then little-known desert ungulate, the Arabian or white oryx Oryx leucoryx, faced extinction as a consequence of hunting and illegal taking throughout its range. But, as a result of direct intervention, a small number of this species was rescued from the wild and taken into captivity. Unlike most species in captivity at that time, the oryx was not to become solely another exhibit for either public entertainment or, to a lesser extent, education, but was from the beginning to be the focus of a captive-breeding programme that had as its objective the reintroduction of the species to the wild (Grimwood, 1962). In 1982, in the central desert of Oman, that objective was met and the Arabian oryx project became the flagship of this new approach to species conservation and one of the most successful conservation stories of our time (Dixon \& Jones, 1988; Stanley Price, 1989; Spalton 1993).

J. A. Spalton (corresponding author) Office of the Adviser for Conservation of the Environment, Diwan of Royal Court, PO Box 246, Muscat 113, Sultanate of Oman. Fax: + 968740 550; E-mail: spalt@gto.net.om

S. A. Brend International Primate Protection League, 116 Judd St, London WC1H 9NS, UK.

M. W. Lawrence 12 Albert Road, Bexley, Kent DA5 INN, UK.

Received 5 March 1999. Accepted 9 March 1999
The success of the Oman oryx reintroduction is not only testimony to the intensive programmes of demographic and genetic management during captive breeding and post release but also to the high degree of political and community support (Stanley Price, 1989). The Oman project met all of 13 criteria proposed for consideration prior to a reintroduction including those relating to the condition of the species, environmental conditions, biopolitical conditions, and biological and other resources (Beck et al., 1994). In a review by Kleiman et al. (1994) the project was one of just 16 of 145 reintroductions that were considered successful. In this paper we describe the success of the Oman programme as the carefully managed population grew almost exponentially from first release in 1982 to reach over 400 in 1996. We then report how, starting in 1996, the resurgence of illegal capture, the cause of the species's decline in the past, led to the collapse of the wild population as oryx were taken for an illegal trade, in which live animals were gifted and sold to private zoos and animal collectors outside Oman.

\section{The Arabian Oryx Sanctuary}

The Arabian Oryx Sanctuary, inscribed on the UNESCO World Heritage List, lies in the central desert of Oman and covers c. 25,000 sq km (Fig. 1). Most of the 


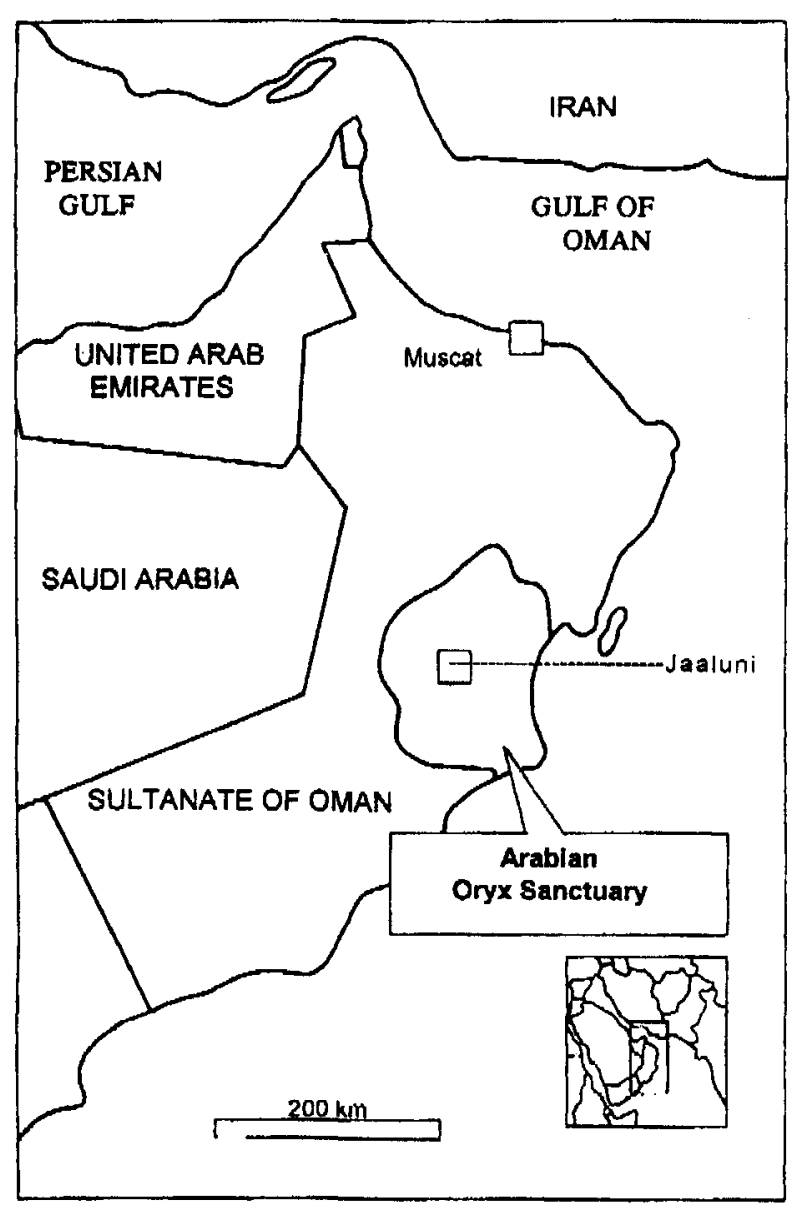

Fig. 1 Location of the Arabian Oryx Sanctuary in the Sultanate of Oman.

sanctuary is a flat or undulating plateau where natural water sources are absent but shallow sandy depressions that act as a sink for surface water are common and are typically well vegetated. The area is hyper-arid desert with a low mean rainfall (39 mm over 1985-95) but as a consequence of the proximity of the sea and the presence of cold water offshore, dewfall and fog are common (Fisher \& Membery, 1998).

The trees Acacia ehrenbergiana and Prosopis cineraria are common in the sandy depressions, and $A$. tortilis occurs on the ridges, providing shade and browse for the sanctuary's herbivores. Ground cover is dominated by perennial shrubs and grasses, in particular the longlived and short-lived perennial grasses Lasiurus hirsutus, Cymbopogon schoenanthus, Panicum turgidum, Chrysopogon sp., Dicanthium foveolatum, Ochthochloa compressa, Stipagrostis paradisea and S. socotrana, which are important food species of the oryx. The sanctuary supports a diverse wildlife community including the Arabian gazelle Gazella gazella cora and the Arabian sand gazelle Gazella subgutturosa marica. Predators include the Arabian wolf Canis lupus arabs, caracal lynx Caracal caracal, honey badger Mellivora capensis, Ruppell's sand fox Vulpes rueppellii and the red fox Vulpes vulpes.

The sanctuary is also the home of Bedouin pastoral nomads who have occupied the area for at least several hundred years. They are primarily stock breeders, who follow rain with their goat and camel herds but in recent years have become increasingly settled, choosing a more sedentary lifestyle around local government centres. At the centre of the sanctuary is Jaaluni, the field headquarters of the White Oryx Reintroduction Project. The project employs 30 local Bedouin as rangers to monitor the oryx herds.

\section{A history of the reintroduction}

Release: 1982

The establishment of a captive World Herd in the USA in 1963 and other captive herds in Arabia was followed by eradication of the species from the wild when the last individuals were killed by poachers in the central desert of the Sultanate of Oman in 1972. However, on the initiative of HM Sultan Qaboos, and following feasibility studies in 1977 and 1978 (Jungius, 1985) the first founder oryx from the World Herd arrived in Jaaluni in central Oman in 1980. Stanley Price (1989) reported in detail the background to the reintroduction, captive management and the progress of the wild population during the first critical years, 1982-86. After a 2-year period of captive management, the first herd of 10 animals was released to the wild on 31 January 1982 , just 10 years after the last wild oryx had been killed $75 \mathrm{~km}$ south-west of Jaaluni (Henderson, 1974). This herd, provided with feed and water, began slowly to explore the desert. After rainfall in August 1982 it moved $20 \mathrm{~km}$ from the release area and switched from the supplementary food to feed on desert grasses and herbs. All the animals were recognizable as individuals and had been named by the Bedouin rangers, who watched them each day, recording important behavioural information. Thus, life in the wild began for the reintroduced oryx (Plate 1 ).

\section{Rainfall and drought: 1983-86}

In April 1983 the sanctuary had the heaviest rainfall since records began in 1979, with $143 \mathrm{~mm}$ recorded at Jaaluni. The released herd, which had grown to 12 by this time, stayed in the Jaaluni area but when further rain fell in August 1983 it moved over $60 \mathrm{~km}$ to find new grazing and remained there through the dry winter of 1983-84. Meanwhile, in April 1984 a second herd 


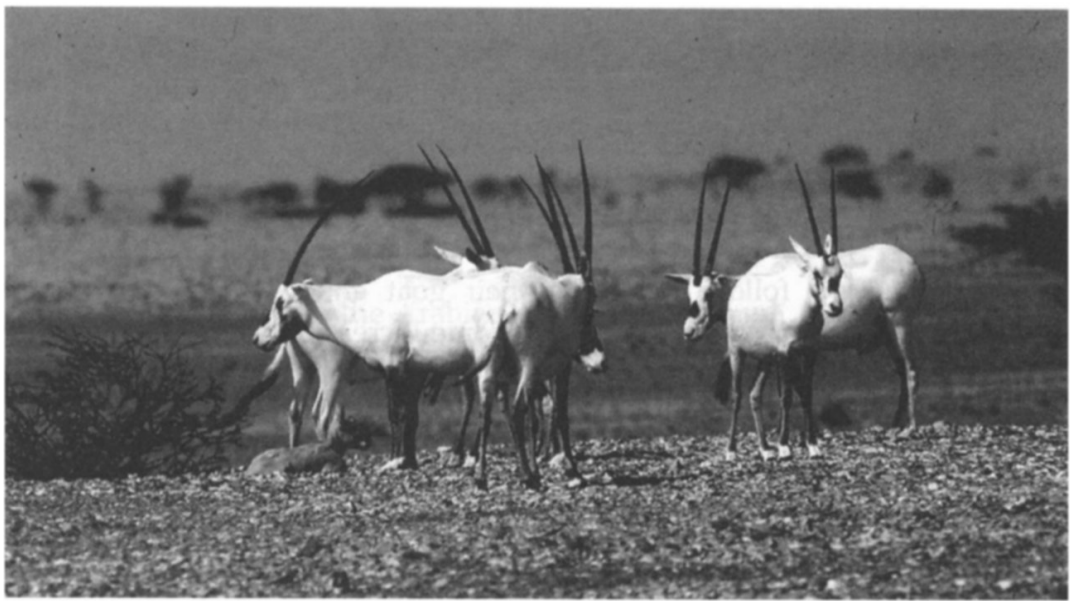

Plate 1 Arabian oryx in the wild,

Arabian Oryx Sanctuary (J. A. Spalton).

of 11 animals (including a male from Jordan) was released to the desert at Jaaluni. However, the desert was dry and this herd never left the supplementary feed at Jaaluni; by June 1984 it was joined by the first herd, which, facing extended drought, had returned to find food and water. These herds, seldom mixing, remained in the Jaaluni area for the following 24 months. A mean annual rate of increase $(r)$ of 0.22 during those years was slow, both as a consequence of the drought conditions and because of the presence of a dominant but sterile founder male, which monopolized potentially fecund females. By June 1986 the population numbered 31 (Fig. 2a).

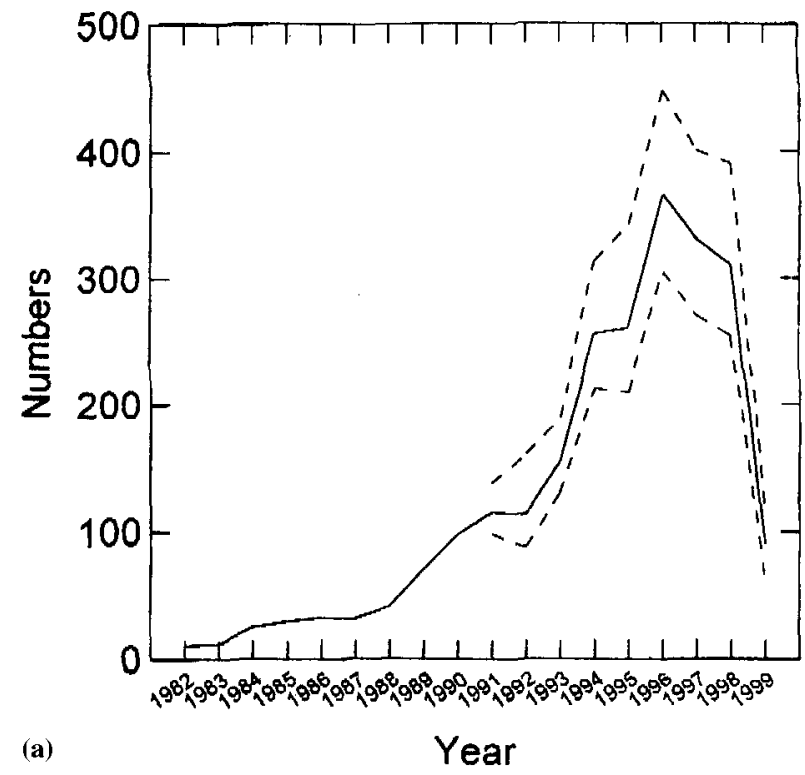

Fig. 2 (a) Numbers of Arabian oryx in the wild, 1982-99. Data are based on a count (1982-90) or Petersen estimate (1991-99) made in March or April of each year. Where the figure is an estimate the 95 per cent upper and lower confidence intervals are shown by a dashed line.
Independence and rapid growth: 1986-90

Following widespread rainfall in June 1986, both herds left the supplementary feed for the last time and moved over $50 \mathrm{~km}$ to fresh grazing. In February 1987 the sterile male was castrated and lost his dominance shortly after. There were further releases of founder animals in 1988 and 1989. These oryx were mainly from the USA but included four from Jordan and four (sired by a Bahraini male oryx) from His Majesty The Sultan's captive-breeding facility in Muscat. These factors and further rainfall in each year from 1987 to 1989 contributed to a more rapid growth rate in the wild population $(r=0.35$ ) from 1986 to 31 December 1989 by

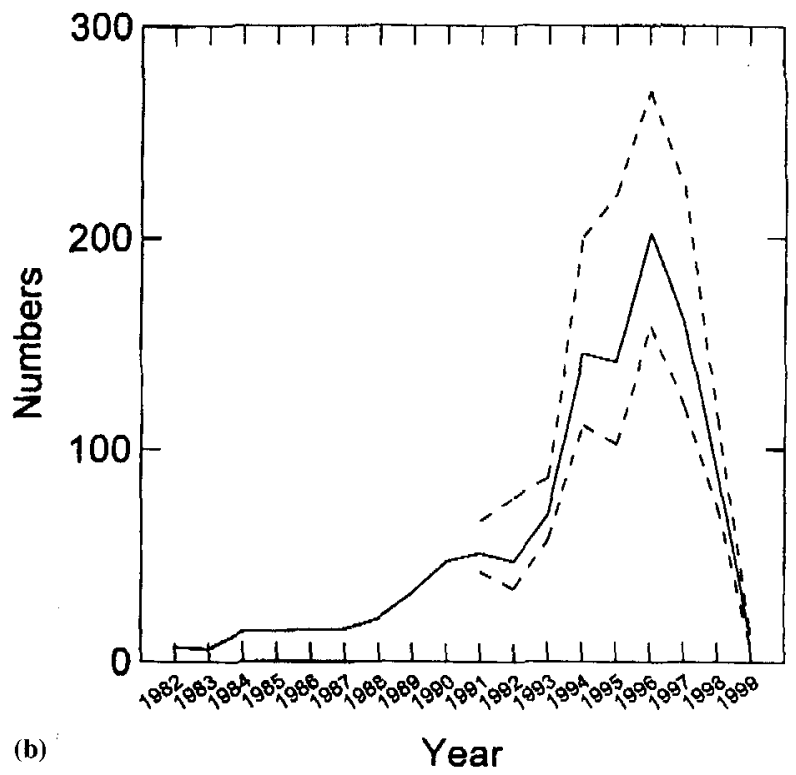

(b) Numbers of female Arabian oryx in the wild, 1982-99. Data are based on a count (1982-90) or Petersen estimate (1991-99) made in March or April of each year. Where the figure is an estimate the 95 per cent upper and lower confidence intervals are shown by a dashed line. 


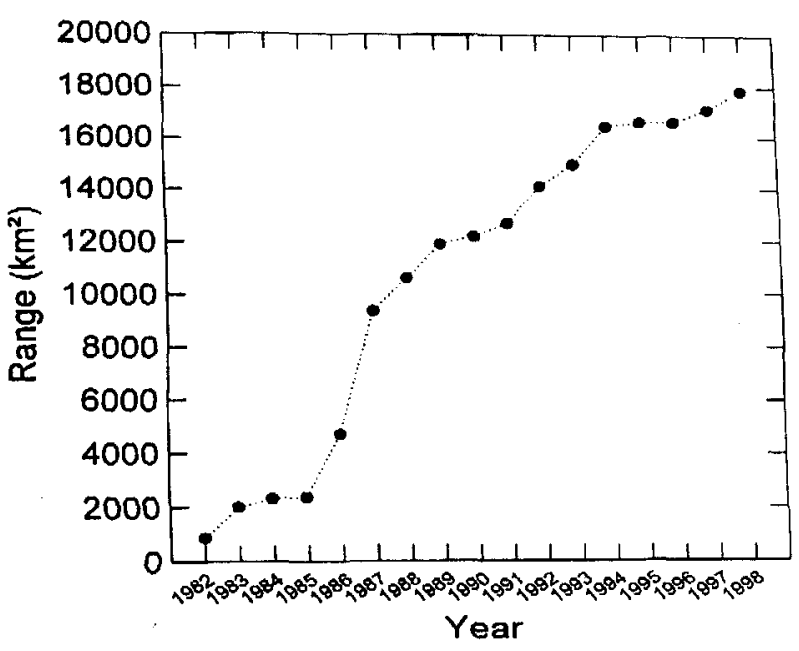

Fig. 3 Cumulative range used by the wild population since release on 31 January 1982 to 31 December 1998. Range or area of occupancy is calculated for the end of each year using the program RANGE, which uses a defined polygon algorithm (Nottrott, 1986).

which time the population numbered 92 animals (Spalton, 1992).

The rains of June 1986 also marked the beginning of a period when the social organization of the oryx began to resemble more closely that seen in other oryx species. Prior to 1986 the population had consisted of two very stable herds that largely reflected the composition of the two released groups. These herds broke up in 1986 and a more dynamic social system developed, with hierarchical dominance that was based on predominantly female groups with following calves. Group size varied and showed frequent changes. Males often left their maternal groups at maturity and there were the first signs of territoriality. The population was using a range of 11,900 sq km by December 1989 (Fig. 3).

\section{A wild population: $1990-95$}

As the wild population passed 100 in early 1990 the oryx monitoring procedure was changed from being individual to population-based. The reasons for this were twofold. First, it became increasingly difficult to follow all individuals, most of which were unmarked. Second, monitoring individuals was no longer necessary because, with large numbers, the threats become increasingly demographic in nature. Thus, a new monitoring strategy was adopted that enabled the collection of detailed information for a sample of known animals and low-level monitoring of all others. Detailed information included breeding performance, genetic profile and health screening, while low-level monitoring comprised twice-yearly surveys for population size and

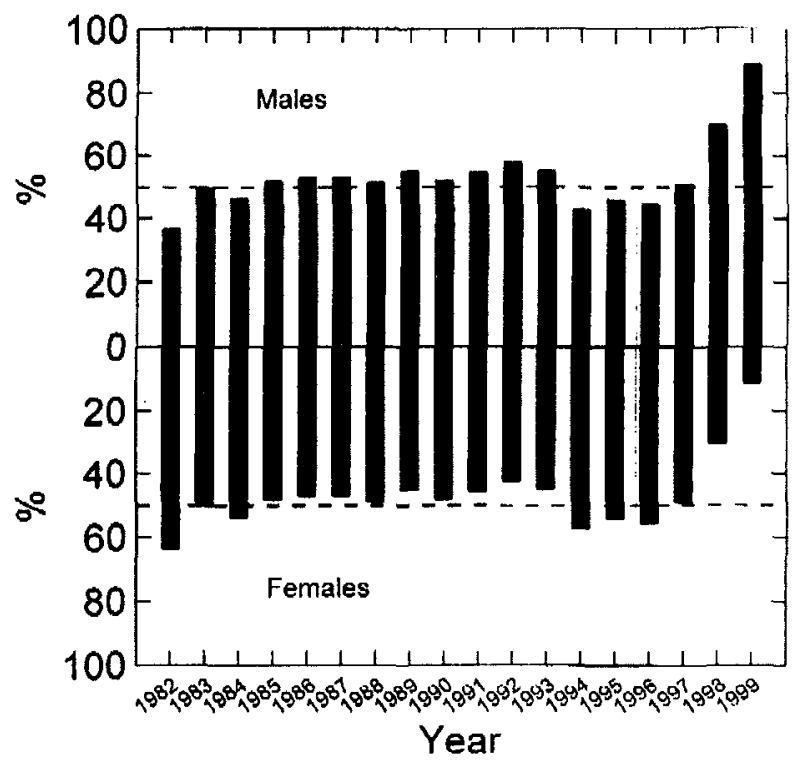

Fig. 4 Sex ratio of the wild Arabian oryx population, 1982-99. Data are based on a count (1982-90) or Petersen estimate (199199) made in March or April of each year.

structure. To facilitate this, some wild-born animals were ear-tagged for individual recognition. Since 1990 annual programmes of immobilization and tagging meant that, at any given time, 20-30 per cent of animals were marked, allowing individuals to be monitored and the criteria for population assessment by mark-recapture methods to be met (Krebs, 1989). The individual identities of all oryx were known until May 1993 and so there was a 2-year period from 1991 during which it was possible to check the accuracy of population surveys that were carried out in March and October of each year.

Although further rain fell in 1990 the rate of population increase $(r)$ slowed to 0.14 during the years 199092 (Fig. 2a). Fecundity remained high but mortality rates among both calves and adult males increased. The main cause of death of calves was aggressive male behaviour during mating attempts with the calves' mothers. The primary cause of death of adult males was fighting and this coincided with increased territoriality among the wild-born males (Spalton, 1993). Localized rain fell in early 1991 and by the autumn of that year it was apparent, as animals began to lose body condition, that the resultant grazing was not sufficient to allow many of the oryx to meet their food requirements. By this time, much of the area had had no rain since February 1990 and the oryx were experiencing their first prolonged drought since that of 1983-86. Supplementary feed was not given and fecundity decreased while mortality rates among the youngest and oldest animals increased. The cause of death identified 
in most cases was malnutrition, and analysis of rumen contents showed levels of dietary crude protein well below predicted maintenance levels of 5-6 percent (Spalton, 1999).

In late January 1992 the drought was broken by light rainfall and the wild population had survived its first test of fitness without supplementary support. Heavy rainfall in March and April of that year led to widespread conception among females that had been barren during the drought. This pattern of response to improved conditions was typical of the wild population, where clear seasonal trends of reproduction were absent and birth dates were principally the result of nutritional factors acting on conception (Spalton, 1995). A further four founders from Muscat were released in October 1992 and by March 1993 the wild population numbered 164. Of these, 90 per cent were desert-born and 24 per cent were aged less than 1 year, indicating a population with a high reproductive potential. Further rain fell in April 1993 and by October the population estimate was 181 (95 per cent CI 157-212) using a range of $14,974 \mathrm{sq} \mathrm{km}$ (Fig. 3).

Typically, oryx will move quickly to areas of new rainfall, with most animals arriving within 28 days (Corp et al., 1998), and in June 1994, after heavy rainfall in the south-east corner of the sanctuary, this response led to the population's range increasing by $1368 \mathrm{sq} \mathrm{km}$ to $16,353 \mathrm{sq} \mathrm{km}$ (Fig. 3). By October 1994, the population estimate was 263 (95 per cent CI 225-314) wild oryx, of which 57 percent were female. A sex ratio skewed towards females was typical of surveys before 1996 (Fig. 4) and, because males are often solitary and more difficult to locate, there was no reason to suspect that it differed from the expected 50:50 that was reported throughout the first years of the reintroduction (Spalton, 1995)

The last founder herd, comprising animals from the USA and Muscat, was released to the wild in April 1995, bringing the total number of individuals released since 1982 to 40 . There was further rainfall and by October 1995 the population numbered 284 (95 per cent CI 243-341) and comprised at least 37 herds of an average size of 4.6 animals, using a total range of $16,623 \mathrm{sq} \mathrm{km}$. Sixteen per cent of the population were aged less than 1 year, with the oldest female being 15 years and the oldest male 17 years. The rate of increase $(r)$ during the years 1992-95 was 0.25 .

Genetic analyses at this time confirmed that the reintroduced population did not carry all the genetic variation of the aboriginal population (Marshall, 1998). However, no associations between inbreeding coefficients (calculated from studbook data) and fitness components were found, although there were associations between measures of microsatellite DNA variation and juvenile survival indicating both inbreeding and outbreeding depression. The analysis concluded that while molecular techniques may prove a more reliable tool for investigating fitness and inbreeding, the high rate of intrinsic growth of the Oman population suggested that simultaneous inbreeding and outbreeding were not major threats to population viability (Marshall \& Spalton, unpublished data).

\section{Poaching and collapse: 1996-99}

Although in the early 1990s poachers had taken Arabian gazelle for live trade, no attempts had been made to capture oryx. However, on 17 February 1996, 14 years after the first release in 1982, and 22 years after the oryx had been exterminated in the wild, poachers again took oryx. White Oryx Project rangers found track evidence showing that poachers in motor vehicles had chased a herd of oryx and captured two calves. Over the following 2 days armed poachers removed further oryx, again targeting calves, some just weeks old. Poaching continued over the next months and by July poachers had switched from calves to adults, probably as a consequence of poor survival rates among stolen calves. Captured calves must have been highly stressed and, given the difficulties of hand rearing wild-born oryx calves, it is unlikely that many survived to reach animal markets outside Oman. Targeting of adult females resulted in abandoned calves, some of which were brought in to Jaaluni for hand rearing (Plate 2).

From track information the White Oryx Project rangers determined that capture methods used by the poachers primarily involved short high-speed chases, with one or two vehicles continually turning the targeted oryx until it either fell exhausted or was knocked over by the poachers' vehicle. Indeed the oryx tends to run straight, avoids cover (where it might escape) and, as the capture team of Operation Oryx found, is relatively easy to capture in open country (Grimwood, 1962). If the oryx failed to recover quickly, the poachers either jumped from the vehicle and caught the animal by hand or with nets. Once captured the animals were usually tied and manhandled into the carrier of a pick-up truck. No cases of shooting oryx were recorded.

In the summer of 1996 poachers, undeterred when encountering either an ear-tagged or heat-branded oryx, took the first of many tagged individuals that had been marked as part of the monitoring programme. Photographic evidence of an oryx found dead outside Oman with its ear tags torn out was supported by results of forensic DNA analysis (Plate 3). Polymorphic microsatellite loci were used to successfully identify a 


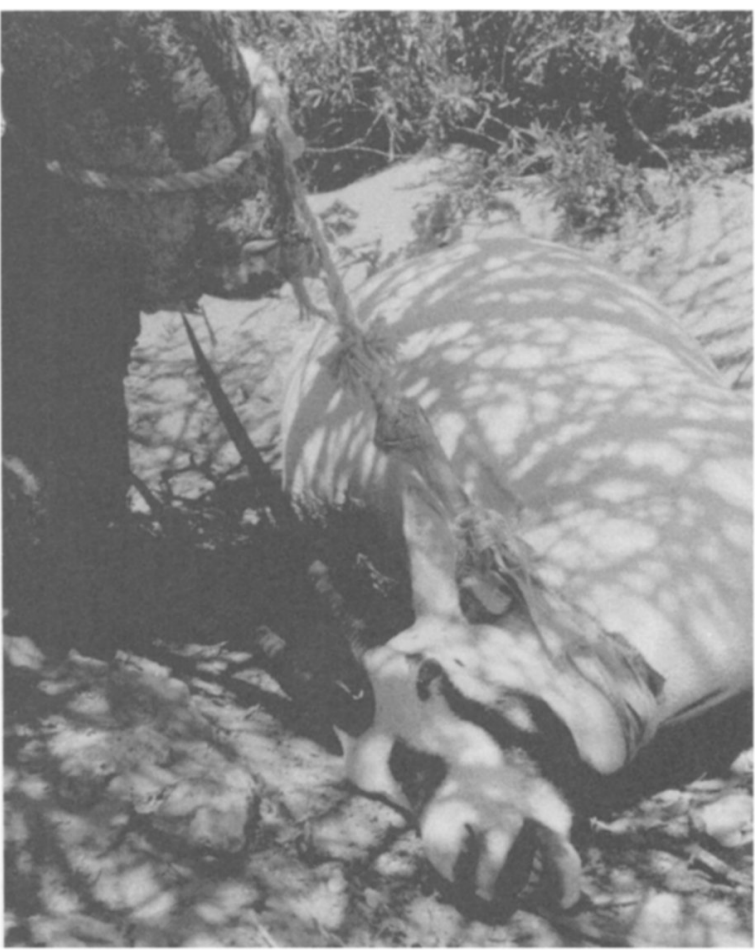

Plate 2 A pregnant female oryx abandoned by poachers while being chased by White Oryx Project rangers. Poachers tied her to a tree, presumably to return later. Post-mortem examination showed that she was about 8 months pregnant, only days from full term (S. A. Brend).

hair sample from this oryx, which had been sampled for DNA analysis previously when immobilized for ear tagging (Marshall et al., unpublished data).

By October 1996 at least 27 oryx were known to have been lost to poachers. However, the bi-annual survey showed that numbers had continued to increase, reaching over 400 oryx. In most cases evidence of poaching came only from track information discovered by the Bedouin rangers who, on the basis of tracks in the sand, can differentiate between vehicle tyres, vehicle models and in some cases can identify individual poachers from their footprints. However, because the three mobile patrols had to cover almost $16,000 \mathrm{sq} \mathrm{km}$ and because poachers were not operating continuously, encounters with poachers were very rare and most poaching was discovered 1-3 days after the incident and only from track information.

Poaching continued through early 1997. Dead oryx abandoned by poachers in the sanctuary and also on routes leading north were testimony to the high rates of mortality associated with this form of illegal capture. Some oryx that were chased, trussed and removed in vehicles at high speed undoubtedly succumbed to capture myopathy, while others died when they were thrown from vehicles by poachers during high-speed chases. Illegal capture was usually by day, often in the late afternoon when the cover of darkness could help with escape. However, moonlit nights were also used for poaching. A survey in April 1997 showed that the population had fallen to an estimated 330 animals (Fig. 2a).

Although poaching continued through the summer of 1997, survey results from October suggested a slight increase in numbers. This was unexpected and the actual population was probably closer to the lower limit of the given 95 per cent confidence intervals. The accuracy of mark-recapture techniques improves with high proportions of marked animals in a population and the White Oryx Project had always marked enough animals for an accuracy of \pm 25 per cent, sufficient for most management work (Krebs, 1989). However, the proportion of marked animals decreased as the population increased with the result that accuracy was reduced at higher population numbers, hence the larger confidence intervals. The poaching of marked animals reduced the accuracy of surveys and analysis still further.

December 1997 witnessed the loss of at least a further 11 oryx, mostly females, bringing the total number of confirmed poaching incidents to 62 . The actual losses were almost certainly much greater because approximately only one-third of all poaching incidents are discovered. By March 1998 the population numbered an estimated 310 (CI 254-390) with a male:female ratio of 216:90, which differed significantly from 50 per cent (Binomial test, $p<0.001$; Figs $2 \mathrm{~b}$ and 4 ). This highly skewed sex ratio further indicated that the poachers were almost certainly targeting females for captivebreeding programmes. In the remaining wild population, the male-biased sex ratio led to increased competition among males for females. This resulted in and consequently increased social pressure on females with probably negative consequences for fecundity and for calf survival because competing males were more aggressive towards following calves.

The final catastrophic collapse in numbers of oryx in the wild occurred during the summer of 1998. By August poachers had removed all but an estimated five oryx (all males) from the southern part of the Sanctuary and White Oryx Project patrols withdrew from that area to protect the few females that remained in the central and northern areas. By late August it was clear that, with continued poaching, the wild population could no longer be considered viable and the decision was taken to establish a captive herd from the animals remaining in the wild. This herd will form the breeding nucleus for future releases when and if the security of the oryx in the wild can be guaranteed. Using both herding and chemical immobilization, 22 oryx, includ- 
Plate 3 A dead oryx found outside Oman. The picture shows clearly where the ear tags have been removed and DNA analysis confirmed that this oryx came from Oman.

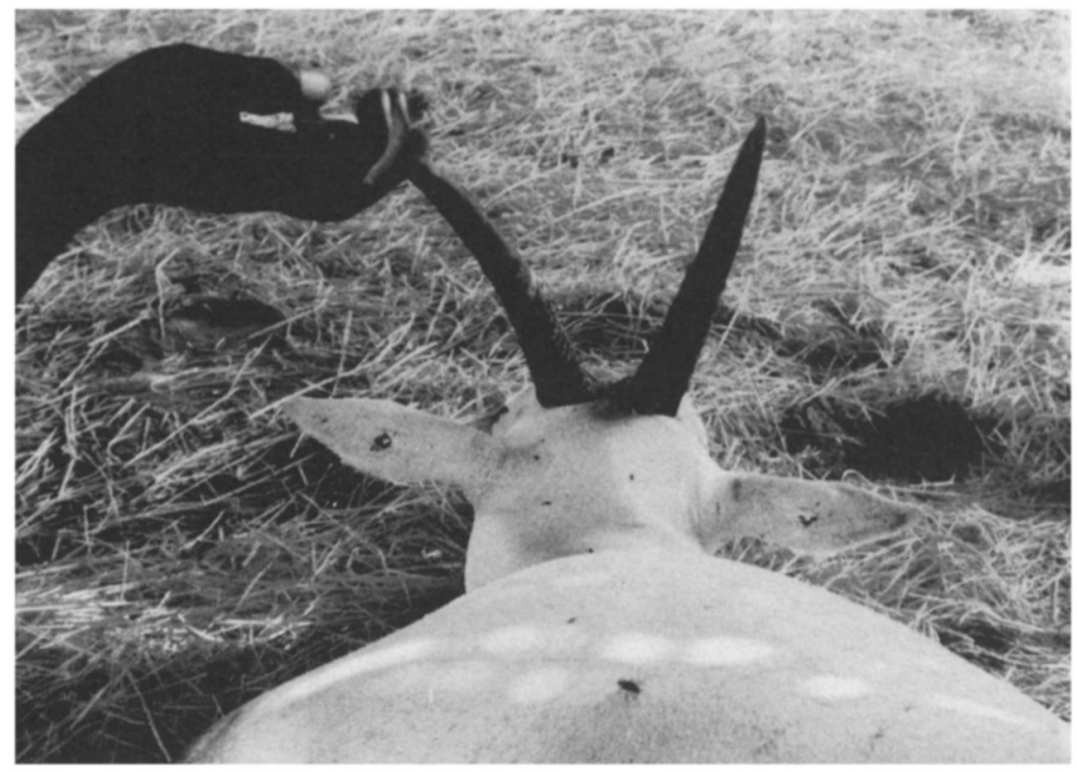

ing a single breeding male, were selected from the wild and brought into the pre-release enclosure at Jaaluni where they joined three orphaned calves to form a herd of 25 ( 6 male, 19 female).

A survey in late September 1998 confirmed that the population had collapsed from an estimated 310 in March to 138 and the male:female ratio was further skewed (108:28). Bachelor herds were increasingly common and only an estimated 20 breeding females remained in the wild, most solitary or in small maledominated herds. Consequently, being difficult to locate and scattered over approximately $5000 \mathrm{sq} \mathrm{km}$, even these few females could not be effectively guarded against poachers. After three females were taken by poachers on 1 day in January 1999 a further 16 oryx were moved from the wild to the Jaaluni enclosure. By late February 1999 the captive herd comprised 40 oryx ( 30 females, 9 males and 1 calf) while 11 females and an estimated 85 males remained in the wild.

\section{The future}

Since poaching of oryx started in February 1996, 28 animals died as a result of natural mortality and 40 are now in captivity at Jaaluni. An estimated 96 individuals remain in the wild. Poachers have removed or killed at least 200 oryx in 3 years.

The remaining wild population will be monitored and guarded against poachers. The captive herd at Jaaluni will be managed with a view to future releases once security in the wild is assured. Measures will be taken to limit social stress and inbreeding to maintain healthy animals. While the genetic background of most of the animals remaining in the wild or in captivity is not known, it is probable that most founder lineages are represented. However, further founder females will be required to speed up the rate of recovery of the wild population and these animals will be selected to maximize genetic diversity and will be subject to the usual health screening and quarantine procedures.

\section{Conclusion}

The Oman population reached a viable number in 1996 as approximately 400 oryx roamed free in the desert. This would have been a fitting end to a long conservation effort that began in 1962 with 'Operation Oryx' and continued with successful programmes of demographic and genetic management in captivity and the wild. The success of the reintroduction can also be attributed to favourable biopolitical conditions and adequate long-term funding, which have been, quite rightly in our opinion, recognized to be as or more important than biological factors for successful reintroduction (Kleiman et al., 1994).

The Oman project met all the criteria necessary for a successful reintroduction. Yet illegal captures since 1996 meant that by 1999,17 years after the first release, the wild population collapsed and is no longer considered viable. The feasibility study for the Arabian oryx reintroduction concluded that the hunting threat that was the cause of the species's decline had been eliminated (Jungius, 1985) and the absence of any security threat to the oryx during the first years of the reintroduction supported this conclusion (Stanley Price, 1989). We do not suggest that this conclusion was wrong but that the threat lay dormant. Once the reintroduction had successfully re-established a large wild oryx popu- 
lation, poachers exploited a demand outside the country for captive animals and thus, illegal capture emerged again as the primary threat to wild oryx.

The large numbers of Arabian oryx in captivity in the region and elsewhere in the world are testimony to the success of captive-breeding programmes. The reintroduction programme in Oman and the establishment in 1995 of a second wild population in the 'Uruq Bani Ma' arid protected area in the Kingdom of Saudi Arabia (Ostrowski et al., 1998) have shown that the oryx can be successfully returned to the wild. The challenge of today is neither captive breeding nor reintroduction but to protect the species in the wild.

\section{References}

Beck, B.B., Rapaport, L.G., Stanley Price, M.R. \& Wilson, A.C. (1994) Reintroduction of captive-born animals. In Creative Conservation: Interactive Management of Wild and Captive Animals (eds P. J. S. Olney, G. M. Mace and A. T. C. Feistner), pp. 287-303. Chapman \& Hall, London.

Corp, N., Spalton, A. \& Gorman, M.L. (1998) The influence of rainfall on range in a female desert ungulate: the Arabian oryx Oryx leucoryx in the Sultanate of Oman. Journal of Zoology, London, 246, 369-377.

Dixon, A. \& Jones, D. (eds) (1988) Conservation and Biology of Desert Antelopes. Christopher Helm, London.

Fisher, M. \& Membery, D.A. (1998) Climate. In Vegetation of the Arabian Peninsula (eds S. A. Ghazanfar and M. Fisher), pp. 5-38. Kluwer Academic, Dordrecht.

Grimwood, I.R. (1962) Operation Oryx. Oryx, 6, 308-334.

Henderson, D.S. (1974) The Arabian oryx: a desert tragedy. National Parks and Conservation Magazine, 48(5), 15-21.

Jungius, H. (1985) The Arabian oryx: its distribution and former habitat in Oman and its reintroduction. Journal of Oman Studies, 8, 49-64.

Kleiman, D.G., Stanley Price, M.R. \& Beck, B.B. (1994) Criteria for reintroductions. In Creative Conservation:
Interactive Management of Wild and Captive Animals (eds P. J. S. Olney, G. M. Mace and A. T. C. Feistner), pp. 287-303. Chapman \& Hall, London.

Krebs, C.J. (1989) Ecological Methodology. Harper \& Row, New York.

Marshall, T.C. (1998) Inbreeding and fitness in wild ungulates. $\mathrm{PhD}$ thesis, University of Edinburgh.

Nottrott, R. (1986) RANGE (Range Analysis Program) User's Guide and Manual. Office of the Adviser for Conservation of the Environment, Muscat, Oman.

Ostrowski, S., Bedin, E., Lenain, D. \& Abuzinada, A.H. (1998) Ten years of Arabian oryx conservation breeding in Saudia Arabia - achievements and regional perspectives. Oryx, 32(3), 209-222.

Spalton, J.A. (1992) The Arabian oryx (Oryx leucoryx) re-introduction project in Oman: 10 years on. In Ungulates 91 (eds F. Spitz, G. Janeau, G. Gonzalez and S. Aulagnier), pp. 342-347. SFEPM, Paris.

Spalton, J.A. (1993) A brief history of the reintroduction of the Arabian oryx (Oryx leucoryx) into Oman 1980-1992. International Zoo Yearbook, 32, 81-90.

Spalton, J.A. (1995) Effects of rainfall on the reproduction and mortality of the Arabian oryx Oryx leucoryx (Pallas) in the Sultanate of Oman. PhD thesis, University of Aberdeen.

Spalton, J.A. (1999) The food supply of Arabian oryx (Oryx leucoryx) in the desert of Oman. Journal of Zoology, London, 247, in press.

Stanley Price, M.R. (1989) Animal Reintroductions: The Arabian Oryx in Oman. Cambridge University Press, Cambridge.

\section{Biosketch}

Andrew Spalton is currently working in the Diwan of Royal Court, Oman. He co-ordinates the Arabian oryx programme and recently developed an environmental tourism programme in the Arabian Oryx Sanctuary. He is currently researching the ecology of wild populations of the endemic Arabian leopard Panthera pardus nimr and Arabian tahr Hemitragus jayakari. 